\title{
Turning Our Gaze to Prosocial Media Effects: What is and isn't Known
}

\author{
SARA PROT [1] \\ Iowa State University, USA \\ DOUGLAS A. GENTILE \\ Iowa State University, USA
}

\begin{abstract}
Clark and Giacomantonio (2015) raise several valuable research questions concerning the relationship between empathy and music genre preferences, and present interesting exploratory analyses concerning this issue. This response provides a review of findings from similar past studies in this area and draws out some of the themes that can help the field progress. An overview is given of established effects of prosocial media use on prosocial behavior in real life as well as past findings concerning empathy as a mediator of these effects. Several key research questions that remain to be explored are also considered (such as a need for research concerning potential mediators and moderators of prosocial media effects).
\end{abstract}

Submitted: 2014, December 1; accepted: 2014 December 2.

KEYWORDS: prosocial behavior, empathy, helping, prosocial media, violent media, General Learning Model

THE article by Clark \& Giacomantonio (2015) reports some interesting exploratory analyses considering whether empathy is related to music genre preferences. As might be expected in a broad question such as genre preferences (which mix many different songs with many different themes together), the effect sizes are all so small that most of them do not achieve the typical accepted levels of statistical significance. Furthermore, many of the claims made seem unlikely to be accurate (e.g. "For the younger sample, MPF-1 $(\mathrm{r}=.03)$ and MPF-2 $(\mathrm{r}=.07)$ had stronger associations with empathy than MPF-3 ( $\mathrm{r}=-.04)$ and MPF-4 $(\mathrm{r}=.03) . "$ [p. 57]). In this example, it is unclear that correlation of .03 and .07 would be significantly larger than -.04 and .03. We do not mean, however, to detract from the valuable research questions that Clark and Giacomantonio raise. Both the strengths and the weaknesses exemplified in their article can be of great benefit to the field. Our goal is to describe the findings of other similar studies and to draw out some of the themes that can help the field progress.

Media research has thrived over the past forty years. Most studies in this area have focused on exploring negative media effects, such as the effects of violent media on aggressive behavior (Anderson et al., 2003, 2010). In addition, there has been increased interest in potential positive effects of prosocial media that portray helpful, caring, and cooperative behaviors. There is now a growing research literature clearly showing that, just as violent media can increase aggression, prosocial media can increase prosocial behavior in both short-term and long-term contexts (Gentile et al., 2009; Greitemeyer, 2011).

One lesson that can be learned from the long history of media violence research is that it is of critical importance to not simply consider the general type or amount of media consumed, but to examine the content. For example, early studies often showed that the total amount of television or video game use predicted increased aggression. By itself, however, this makes little theoretical sense. Why should television or video games in general increase aggression? Once studies began to separate out the violent content from the amount of media consumed, then theoretical clarity was gained. To oversimplify, amount of media predicts outcomes that can be explained (usually) by displacement of time. For example, greater amount predicts poorer school performance (Anderson, Gentile, \& Buckley, 2007) and increased risk of obesity (Laurson et al., 2008; theoretically because every hour sitting in front of a screen is one not spent reading, doing homework, or exercising). Amount by itself is not a good predictor of aggressive behavior, but violent content is. Studies that have separated amount from content consistently show that violent 
content predicts aggressive attitudes, beliefs, and behaviors (e.g. Anderson, Gentile, \& Buckley, 2007; Gentile, 2011). Many newer studies of prosocial effects of media have therefore focused on the prosocial content, rather than simply examining the total amount or broad genre.

Prosocial media content effects on prosocial behavior have been demonstrated using diverse research methods. Cross-sectional studies show positive associations between prosocial media use and different types of prosocial behavior in real life (Sprafkin \& Rubinstein, 1979; Gentile et al., 2009). Several early studies found that watching prosocial television shows is significantly related to prosocial attitudes and helpful behavior among children and adults (Anderson et al., 2000; Rosenkoetter, 1999; Sprafkin \& Rubinstein, 1979). Playing prosocial video games is positively associated with helping, cooperation, and sharing (Gentile et al., 2009; Prot et al., 2014).

Laboratory experiments support the idea that prosocial media use causes increased prosocial behavior in the immediate situation (Gentile et al., 2009; Greitemeyer \& Osswald, 2010; Greitemeyer, Osswald, \& Brauer, 2010; Saleem, Anderson, \& Gentile, 2012a). For example, Gentile and colleagues (2009) randomly assigned participants to play a prosocial, violent or neutral video game. Helping behavior was measured using the tangram task in which participants assigned an anonymous partner easy, moderate, or difficult tangram puzzles. Participants were told that the partner would win money if he or she completed enough puzzles in 10 minutes. Playing a prosocial video game for only 20 minutes prompted participants to be more helpful toward the partner by assigning them more easy puzzles. Similar short-term effects have been found for listening to music with prosocial lyrics (Greitemeyer, 2009a, 2009b; Greitemeyer \& Schwab, 2014). In one study, $53 \%$ of participants were willing to donate money to a nonprofit organization after listening to songs with prosocial lyrics, compared to $31 \%$ among participants who listened to neutral songs (Greitemeyer, 2009a). Listening to music with pro-equality lyrics (such as the song "Respect" by Aretha Franklin) prompted participants to show more positive attitudes and behavior toward women (Greitemeyer, Hollingdale, \& Traut-Mattausch, 2012). Such short-term effects of prosocial media use shown in the lab seem to generalize well to everyday situations (e.g. prosocial music increases tipping at a restaurant; Jacob, Guéguen, \& Boulbry, 2010).

Longitudinal studies demonstrate long-term effects of prosocial media use on prosocial behavior. For example, children who watched the prosocial television show Blues Clues were found to engage in more frequent subsequent prosocial behavior over a period of two years (Anderson et al., 2000). Gentile and colleagues (2009) found that prosocial video game use significantly predicted prosocial behavior among children and adolescents measured three to four months later, even when statistically controlling initial levels of prosocial behavior. Additionally, earlier prosocial behavior predicted later prosocial video gaming, suggesting the existence of an upward spiral of prosocial gaming and behavior. Longitudinal relations among prosocial media use and prosocial behavior generalize across culture, sex, and age groups (Prot et al., 2014).

In sum, research evidence from studies using a wide range of methods converges to show that prosocial content in media can increase different types of prosocial behavior. This finding is also supported by meta-analytic reviews (Mares \& Woodard, 2005; Greitemeyer \& Mügge, 2014). For example, a recent meta-analysis combined results from 27 experimental, cross-sectional, and longitudinal studies involving a total of 5880 participants and showed clear evidence that prosocial video game exposure decreases aggression and increases helping across different types of studies (Greitemeyer \& Mügge, 2014).

Theoretically, there could be several mechanisms through which prosocial content could operate. These include empathy, perspective-taking, compassion, mindfulness, positive mood, and so on. There has been very little work to date on any of these mechanisms except empathy, and indeed, empathy seems to be one mechanism underlying prosocial media effects on prosocial behavior. Playing a prosocial video game increases empathy and decreases schadenfreude in the short term (Greitemeyer, Osswald, \& Brauer, 2010). Listening to songs with prosocial lyrics increases helping behavior in the immediate situation by increasing empathy (Greitemeyer, 2009b). Cross-sectional data from Western, East European, and East Asian countries suggests that consumption of prosocial movies, television shows, and video games predicts increased prosocial behavior via increased empathy (Prot et al., 2014). Furthermore, evidence from a twoyear longitudinal study supports the idea that trait empathy is a significant mediator of long-term effects of prosocial media use on prosocial behavior (Prot et al., 2014). There is evidence that cognitive mediators (such as accessibility of prosocial thoughts) account for short-term effects of prosocial media on helping (e.g. Greitemeyer \& Osswald, 2010), but the current limited research evidence suggests that long-term (two-year) prosocial media effects are fully mediated by changes in trait empathy (Prot et al., 2014). That said, there are many other possible mediators that have not yet received study. For example, even 9-month- 
old babies can discriminate happy and sad music (Flom, Gentile, \& Pick, 2008), suggesting that mood induction (emotional empathy) could also be a potential mechanism.

There are several theoretical models that can inform research on prosocial media effects, including social learning theory, cognitive neoassociation theory, as well as developmental theories of moral development. The General Learning Model (GLM: Buckley \& Anderson, 2006; Gentile, Groves, \& Gentile, 2014; Maier \& Gentile, 2012) provides a broad framework and has been used to frame a majority of prosocial media effect studies. The GLM proposes that social behaviors and attitudes are learned from real-life experiences and from the media through a variety of learning mechanisms. What is learned largely depends on content. Whereas observing violent actions increases the likelihood of aggressive behavior (Anderson et al., 2003), observing prosocial content that shows characters helping each other in nonviolent ways increases the likelihood of prosocial behavior. In the short-term, prosocial media are expected to exert effects by priming prosocial cognitions (Greitemeyer, 2011), generating positive affect (Saleem, Anderson, \& Gentile, 2012a, 2012b), and prompting empathetic responses in the current social interaction (Greitemeyer, 2009b). Over time, habitual prosocial media use can lead to stable changes in beliefs, attitudes, behavioral scripts, and affective traits (such as increased trait empathy; Prot et al., 2014).

There is good evidence that use of prosocial media (including prosocial television shows, movies, music, and video games) leads to increased prosocial behavior in real life. This evidence is especially convincing given that converging findings exist from studies using diverse methods and media (Greitemeyer \& Mügge, 2014). Nonetheless, many key research questions still remain to be explored. For example, although there are several studies pointing to empathy as a key mechanism of prosocial media effects, more research is needed to demonstrate under which circumstances other cognitive and affective mediators play a significant role (such as prosocial thoughts, caring attitudes, perceptual biases, beliefs about the moral self, and so on), and what moderators may enhance or mitigate those effects (e.g. mindfulness, sex, age, mood, prior desensitization, and so on). Theoretical models such as social learning theory (Bandura, 1973) and the General Learning Model provide useful frameworks that can guide future research efforts in this area. Although most research in the field of media effects has focused on negative effects of violent media, it is equally important to examine how, and under what circumstances, prosocial media can promote empathetic responding, helping, and cooperation while reducing aggression and discrimination.

\section{NOTES}

[1] Correspondence concerning this article should be addressed to: Sara Prot, Department of Psychology, Iowa State University, W112 Lagomarcino Hall, Ames, IA 50011-3180. Email: sprot@iastate.edu

\section{REFERENCES}

Anderson, C. A., Berkowitz, L., Donnerstein, E., Huesmann, R. L., Johnson, J., Linz, D., Malamuth, N., \& Wartella, E. (2003). The influence of media violence on youth. Psychological Science in the Public Interest, 4, 81-110.

Anderson, C. A., Gentile, D. A., \& Buckley, K. E. (2007). Violent video game effects on children and adolescents: Theory, research, and public policy. New York: Oxford University Press.

Anderson, C. A., Shibuya, A., Ihori, N., Swing, E. L., Bushman, B.J., Sakamoto, A., Rothstein, H. R., \& Saleem, M. (2010). Violent video game effects on aggression, empathy, and prosocial behavior in Eastern and Western countries. Psychological Bulletin, 136, 151-173.

Anderson, D., Bryant, J., Wilder, A., Santomero, A., Williams, M., \& Crawley, A. M. (2000). Researching Blue's Clues: Viewing behavior and impact. Media Psychology, 2, 179-194.

Bandura, A. (1973). Aggression: A social learning analysis. Englewood Cliffs, NJ: Prentice-Hall. 
Buckley, K. E., \& Anderson, C. A. (2006). A theoretical model of the effects and consequences of playing video games. In P. Vorderer \& J. Bryant (Eds.), Playing video games - Motives, responses, and consequences (pp. 363-378). Mahwah, NJ: LEA.

Clark, S. S., \& Giacomantonio, S. G. (2015). Toward predicting prosocial behavior: Music preference and empathy differences between adolescents and adults. Empirical Musicology Review, 10(1), 50-65.

Flom, R. A., Gentile, D. A., \& Pick, A. D. (2008). Infants' discrimination of happy and sad music. Infant Behavior and Development, 31, 716-728.

Gentile, D. A. (2011). The multiple dimensions of video game effects. Child Development Perspectives, 5, 75-81.

Gentile, D. A., Anderson, C. A., Yukawa, N., Saleem, M., Lim, K. M., Shibuya, A., Liau, A. K., Khoo, A., Bushman, B. J., Huesmann, L. R., \& Sakamoto, A. (2009). The effects of prosocial video games on prosocial behaviors: International evidence from correlational, longitudinal, and experimental studies. Personality and Social Psychology Bulletin, 35, 752-763.

Gentile, D. A., Groves, C., \& Gentile, J. R. (2014). The general learning model: Unveiling the learning potential form video games. In F. C. Blumberg (Ed.), Learning by playing: Frontiers of video gaming in education (pp. 121-142). New York: Oxford University Press.

Greitemeyer, T. (2009a). Effects of songs with prosocial lyrics on prosocial thoughts, affect, and behavior. Journal of Experimental Social Psychology, 45, 186-190.

Greitemeyer T. (2009b). Effects of songs with prosocial lyrics on prosocial behavior: Further evidence and a mediating mechanism. Personality and Social Psychology Bulletin, 35, 1500-1511.

Greitemeyer, T. (2011). Effects of prosocial media on social behavior: When and why does media exposure affect helping and aggression. Current Directions in Psychological Science, 20, 251-255.

Greitemeyer, T., Hollingdale, J., \& Traut-Mattausch, E. (2012). Changing the track in music and misogyny: Listening to music with pro-equality lyrics improves attitudes and behavior toward women. Psychology of Popular Media Culture (Nov 12, 2012, online).

Greitemeyer, T., \& Mügge, D. O. (2014). Video games do affect social outcomes: A meta-analytic review of the effects of violent and prosocial video game play. Personality and Social Psychology Bulletin, 40, 578-589.

Greitemeyer, T., \& Osswald, S. (2010). Effects of prosocial video games on prosocial behavior. Journal of Personality and Social Psychology, 98, 211-221.

Greitemeyer, T., Osswald, S. \& Brauer, M. (2010). Playing prosocial video games increases empathy and decreases schadenfreude. Emotion, 6, 796-802.

Greitemeyer, T., \& Schwab, A. (2014). Employing music exposure to reduce prejudice and discrimination. Aggressive Behavior, 40, 542-551.

Jacob, C., Guéguen, N., \& Boulbry, G. (2010). Effects of songs with prosocial lyrics on tipping behavior in a restaurant. International Journal of Hospitality Management, 29, 761-763.

Laurson, K., Eisenmann, J. C., Welk, G. J., Wickel, E. E., Gentile, D. A., \& Walsh, D. A. (2008). Combined influence of physical activity and screen time recommendations on childhood overweight. Journal of Pediatrics, 153, 209-214. 
Maier, J. A., \& Gentile, D. A. (2012). Learning aggression through the media: Comparing psychological and communication approaches. In L. J. Shrum (Ed.), The psychology of entertainment media: Blurring the lines between entertainment and persuasion (2nd ed., pp. 267-299). New York, NY: Taylor \& Francis.

Mares, M. L., \& Woodard, E. (2005). Positive effects of television on children's social interactions: A meta-analysis. Media Psychology, 7, 301-322.

Prot, S., Gentile, D. G., Anderson, C. A., Suzuki, K., Swing, E., Lim, K. M., Horiuchi, Y., Jelic, M., Krahé, B., Liuqing, W., Liau, A., Khoo, A., Petrescu, P. D., Sakamoto, A., Tajima, S., Toma, R. A., Warburton, W. A., Zhang, X., \& Lam, C. P. (2014). Long-term relations between prosocial media use, empathy and prosocial behavior. Psychological Science, 25, 358-368.

Rosenkoetter, L. I. (1999), The television situation comedy and children's prosocial behavior. Journal of Applied Social Psychology, 29, 979-993.

Saleem, M., Anderson, C. A., \& Gentile, D. A. (2012a). Effects of prosocial, neutral, and violent video games on children's helpful and hurtful behaviors. Aggressive Behavior, 38, 281-287.

Saleem, M., Anderson, C. A., \& Gentile, D. A. (2012b). Effects of prosocial, neutral, and violent video games on college students' affect. Aggressive Behavior, 38, 263-271.

Sprafkin, J. N., \& Rubinstein, E. A. (1979). Children's television viewing habits and prosocial behavior: A field correlational study. Journal of Broadcasting, 23, 265-276. 